PII:S1350-6307(96)00008-8

\title{
TOOTH BENDING FATIGUE FAILURES IN GEARS
}

\author{
P. J. L. FERNANDES \\ Metallurgical and Corrosion Services, MATTEK, CSIR, Private Bag X28, Auckland Park, 2006, South Africa
}

(Received 13 March 1996)

\begin{abstract}
Tooth bending fatigue is one of the most common modes of fatigue failure in gears. It results in progressive damage to gear teeth and ultimately leads to complete failure of the gear. The characteristics of this failure mode are discussed in detail and a number of actual case studies are presented which show the occurrence of this failure mode in practice. Copyright (C) 1996 Elsevier Science Ltd.
\end{abstract}

\section{INTRODUCTION}

A gear is a machine element designed to transmit force and motion from one mechanical unit to another. The design and function of gears are usually closely associated, since gears are designed for a specific function. Various types of gears have been developed to perform different functions, the most common of these being spur gears, helical gears, straight and spiral bevel gears, and hypoid gears. The characteristics of these various gear types are discussed in most mechanical design texts (e.g. [1]).

Like all mechanical components, gears can and do fail in service for a variety of reasons. In most cases, except for an increase in noise level and vibration, total gear failure is often the first and only indication of a problem. Many modes of gear failure have been identified, for example fatigue, impact, wear or plastic deformation. Of these, one of the most common causes of gear failure is tooth bending fatigue.

\section{TOOTH BENDING FATIGUE}

The stresses on a gear tooth can be analysed by considering the tooth to be a short cantilever beam with the load applied at the bearing surface. This is shown schematically in Fig. 1. The maximum tensile stresses occur at the root radius on the active (i.e. loaded) flank of the gear tooth, while the maximum compressive stresses occur at the root radius on the passive flank. A zero-stress point therefore exists below the root circle at or near the tooth centre-line. Depending on the geometry of the gear tooth and the characteristics of loading, the stress concentration at the root radius where maximum tensile stresses are experienced may vary from 1.4 to 2.5 [2]. With the cyclic variation in loads characteristic of gear operation, these regions become preferential sites for fatigue crack initiation.

Once a fatigue crack initiates at the root radius, it propagates towards the zero-stress point, which is initially below the root circle near the tooth centre-line [3]. However, as crack propagation proceeds, the zero-stress point is displaced laterally until it reaches a position under the opposite root. At this stage, the shortest uncracked section lies between the crack tip and the opposite root, and final crack growth proceeds in this direction. This results in the L-shaped crack paths often observed in practice and shown schematically in Fig. 2.

As the fatigue crack propagates, the cracked tooth is deflected, thus allowing the adjacent gear teeth to pick up the load. This is also shown in Fig. 2. The higher loads on these teeth, in turn, impose higher stresses at the corresponding root radii and lead to further fatigue crack initiation. As a result, tooth bending fatigue usually leads to failure of a number of adjacent gear teeth. 


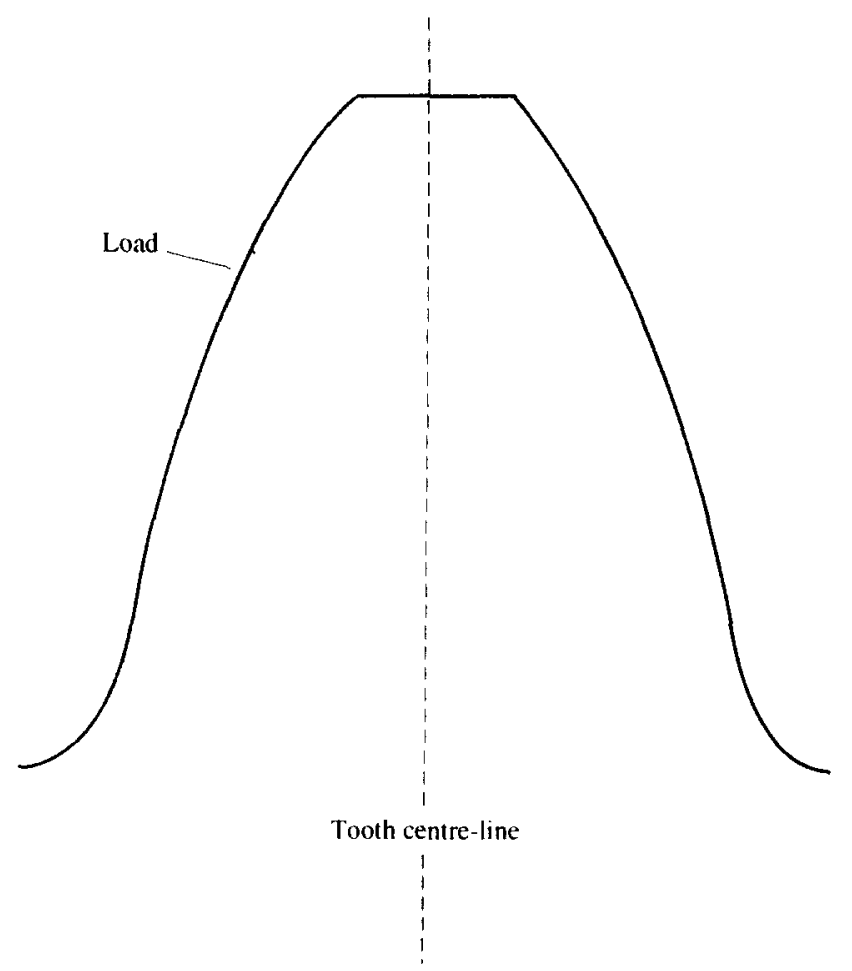

Fig. 1. Schematic diagram of a gear tooth as a short cantilever beam.

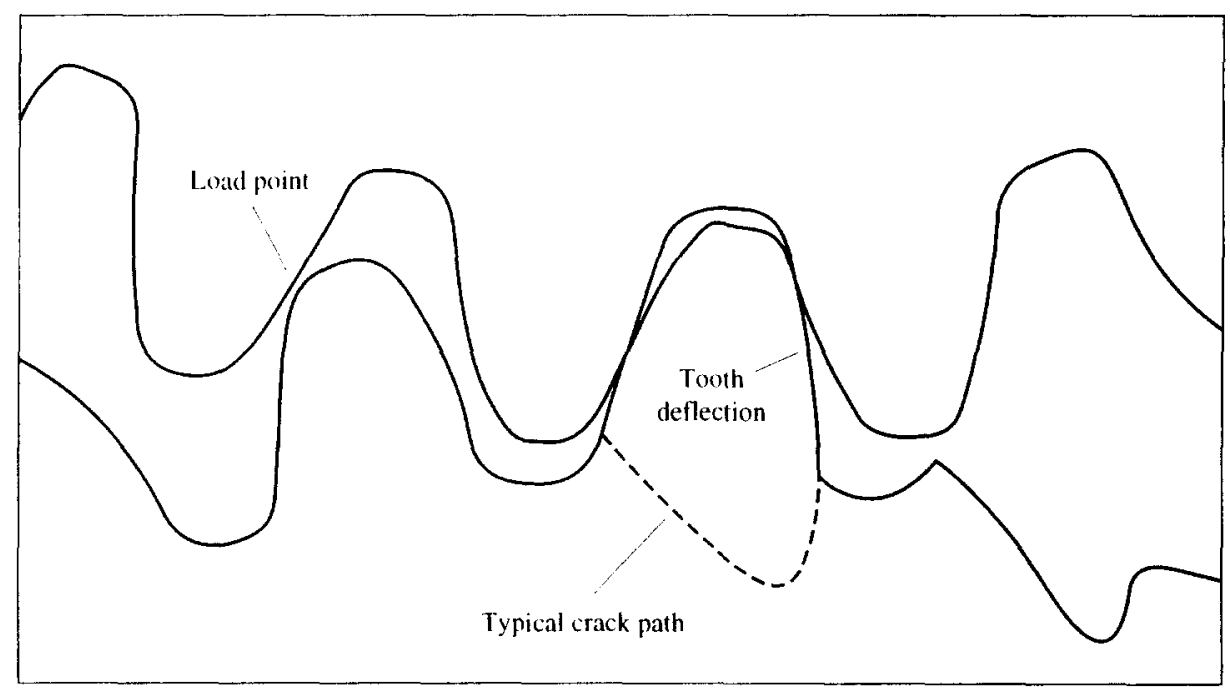

Fig. 2. Schematic diagram showing the typical path followed by a tooth bending fatigue crack.

Several causes of tooth bending fatigue failure have been identified. These include poor design of the gear sets, incorrect assembly or misalignment of the gears, overloads, inadvertent stress raisers or subsurface defects in critical areas, and the use of incorrect materials and heat treatments [4]. In the following sections, a number of case studies are presented which illustrate tooth bending fatigue in various types of gears.

\section{CASE STUDY 1-SPIRAL BEVEL GEAR}

\subsection{Background}

A gearbox was used on the right-hand side of a dual-drive conveyor system for several months without any reported failures. During this time, the left-hand side gearbox failed 
several times. The right-hand side gearbox was subsequently transferred to the left-hand side and failure of a spiral bevel gear set occurred after 2 weeks [5]. While on the right-hand side, the spiral bevel gear was loaded on the concave face of the gear teeth. However, when placed on the left-hand side, the operating direction was reversed and the loading on the same spiral bevel gear was on the convex side of the teeth.

\subsection{Metallurgical examination}

Visual examination of the failed gear showed that a number of adjacent gear teeth had failed by fatigue (Fig. 3). Distinct clam-shell markings were evident and indicated the crack initiation sites to be at the root radii on the convex side of the gear teeth. Furthermore, these initiation sites were not centred along the length of the teeth but were closer to the toe of the gear. Magnetic particle inspection of the gear showed several other cracks originating at the root radii on the convex side of adjacent gear teeth.

Examination of the undamaged teeth showed that the contact pattern on the concave side of the teeth was centred midway between the ends of the teeth and covered the top two-thirds of the tooth height. On the other hand, the contact pattern on the convex side of the teeth was displaced towards the toe and covered only the top one-third of the tooth height.

The material of construction of the gear was found to be En $39 \mathrm{~B}$, in compliance with the design specification. A metallographic analysis of this material showed the microstructure to consist of fine tempered martensite. Furthermore, microhardness tests carried out on a section perpendicular to the surface confirmed that case-hardening had been carried out according to the specified requirements.

\subsection{Analysis}

The contact pattern on the concave side of the gear teeth indicates that, while the gearbox was operating on the right-hand side of the dual-drive system, an optimum load distribution on the gear teeth was achieved. This is in agreement with the fact that no failure was reported over the several months the gearbox was operated in this direction. However, when the gearbox was transferred to the left-hand side of the dual-drive system and the direction of operation reversed, the resulting loads on the spiral bevel gear teeth were concentrated high

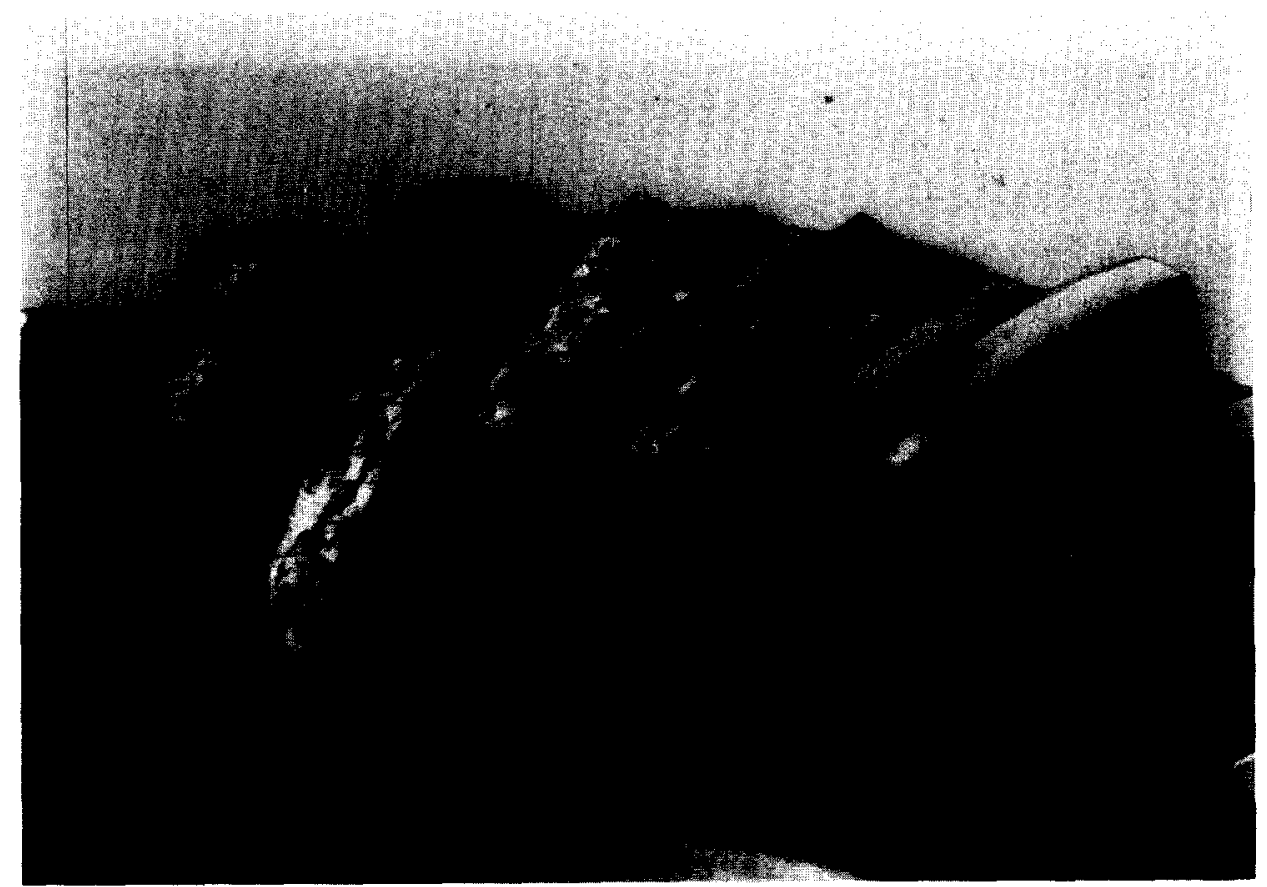

Fig. 3. Close-up view of the fracture surfaces of adjacent teeth on the spiral bevel gear. 
on the tooth flank and near the toe. This is indicated by the contact pattern on the convex side of the gear teeth. Under these conditions, the resulting stresses at the root radii in the region of the gear toe were increased and fatigue crack initiation resulted. Examination of Fig. 3 shows that in all cases the fatigue crack initiation sites were near the toe.

The tooth bending fatigue failure in this case was therefore as a result of an incorrect load distribution on the gear teeth. This may have been due to misalignment of the gear-train or it may be that this particular gear-train was not set to run in both directions. In cases where gears are expected to run in two directions, it is recommended that the gears be set and checked in both directions before being placed in operation.

\section{CASE STUDY 2-HELICAL GEAR}

\subsection{Background}

Over a period of 18 months, several failures of gears from an extruder reduction gearbox were reported [6]. In each case, failure resulted in the cracking of one or more gear teeth from a helical gear, which subsequently had to be replaced. At one stage, failure of a number of gear teeth occurred after only 2 days' operation. The gearbox in this case was reported to be running hot and with excessive vibration.

\subsection{Metallurgical examination}

Examination of the failed gear showed that a number of adjacent teeth had failed by fatigue cracking. Clam-shell markings indicative of fatigue failure were clearly discernible on the fracture surfaces. The origins of the cracks were at the root radii close to one end of the teeth. Cracking had progressed across the base of the gear teeth and resulted in complete removal of approximately $25 \%$ of the tooth length.

A chemical analysis of the material of construction showed it to be En 36B, a nickelchromium case-hardening steel. With the correct heat treatment, this material can be case-hardened and its microstructure transformed to martensite. A metallographic analysis of the failed gear showed the microstructure to consist of three distinct regions: a decarburized surface layer consisting mostly of ferrite, an underlying region consisting of tempered martensite, and the core consisting of a mixture of ferrite and martensite. These three regions are shown in Fig. 4. The presence of a decarburized surface layer as well as the absence of a

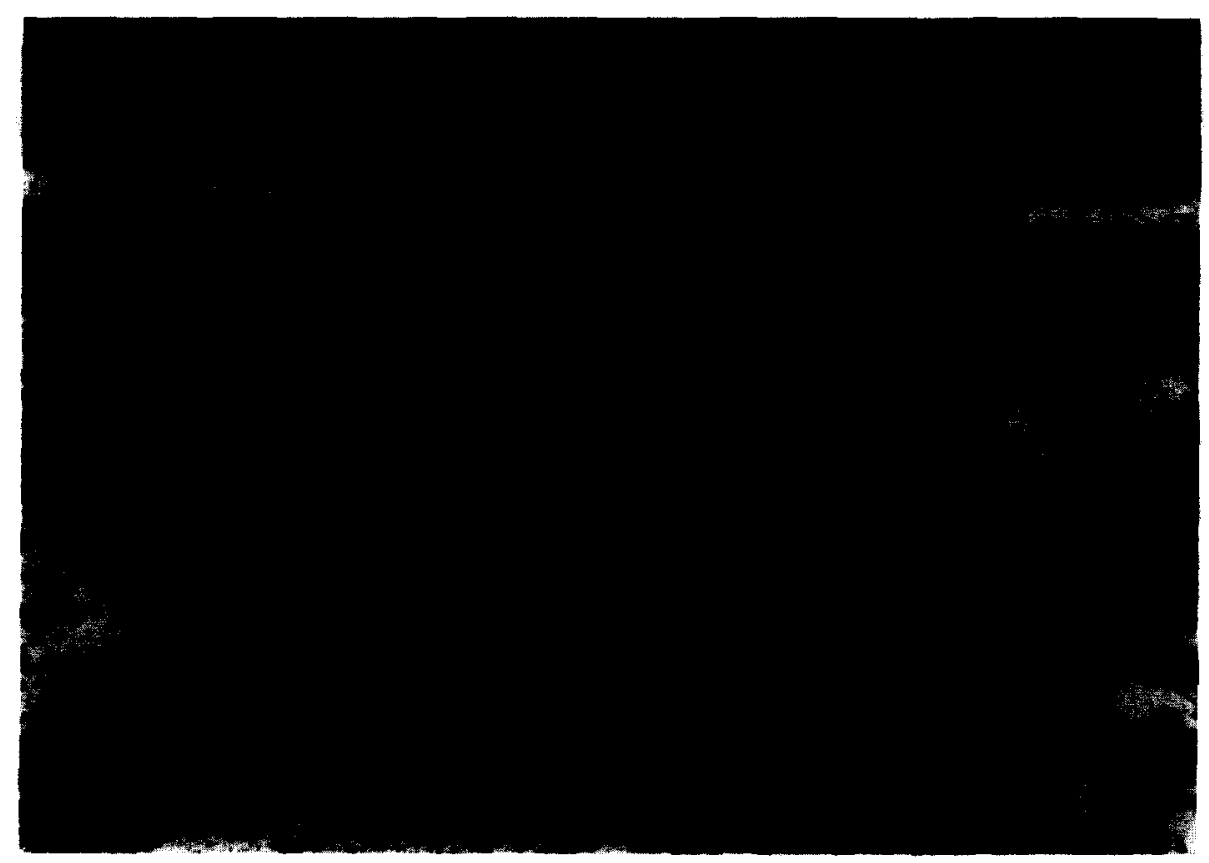

Fig. 4. Micrograph showing the microstructure of the helical gear. Three distinct regions are discernable. 
fully martensite microstructure in the core of the gear indicates that this gear was incorrectly heat-treated.

\subsection{Analysis}

The primary reason for case-hardening gears is to produce a hard and wear-resistant case on the surface while maintaining a tough core. One of the consequences of the process is that residual compressive stresses are induced in the case, and these significantly increase the resistance to fatigue crack initiation.

In the gear examined, the case-hardening process had not been carried out successfully and had resulted in the formation of a decarburized surface layer. The resulting microstructure in this region was predominantly ferrite, which is considerably softer than martensite. This was confirmed by performing micro-hardness measurements across the three regions shown in Fig. 4. In the absence of correct case-hardening, the resistance to fatigue crack initiation was therefore reduced and it is possible that cracking could occur even under normal operating loads.

In addition to the incorrectly heat-treated material, it appears that misalignment of the gear in the gearbox may also have had a contributing effect on the failure. In all cases the crack initiation sites were close to one end of the gear teeth, suggesting that the loads were highest in this region. This, in turn, implies that there was incorrect contact between the gear teeth, possibly resulting from misalignment. Examination of the contact pattern on the matching gear supported this hypothesis.

\section{CASE STUDY 3-SPUR GEARS}

\subsection{Background}

A malfunction in a component in a canning plant reportedly resulted in deformation of a shaft used to drive a set of spur gears. This component was, nevertheless, maintained in service and a further 1.6 million cans were produced before fracture of several teeth on the gears occurred [7]. The gears included a solid and a ring spur gear.

\subsection{Metallurgical examination}

Visual examination of the gears showed that the gear teeth failed by fatigue, with the cracks originating at the root radii. In addition, severe spalling was evident on the contact surfaces of some of the remaining teeth. This was particularly severe on the solid spur gear, and in all cases spalling was predominant towards one side of the gear teeth. Magnetic particle inspection of both gears showed fatigue cracking at the root radii on both sides of many of the remaining gear teeth. This is shown in Fig. 5. Furthermore, in the case of the ring gear, cracking at the root radii was associated with the presence of a threaded locating hole (Fig. 6).

\subsection{Analysis}

The severe spalling observed on the contact surfaces of some of the gear teeth results from subsurface fatigue due to high Hertzian stresses, and is indicative of extremely high operating loads. These loads, in turn, impose severe stresses at the root radii and induce fatigue crack initiation. In the ring gear, the presence of a hole close to the root circle further acts as a stress concentration site and serves to deflect the fatigue crack. As such, the L-shaped crack path, typical of tooth bending fatigue, is not observed. The presence of fatigue cracks on both sides of the gear teeth suggests that the failed gears were operated in both directions. This is normal practice in the case of spur gears.

The high operating loads were undoubtedly due to the deformation of the shaft reported to have occurred prior to the gear failures. Any misalignment in the gear-train, including the drive shaft, may result in extraordinarily high loads on the related components, and may 


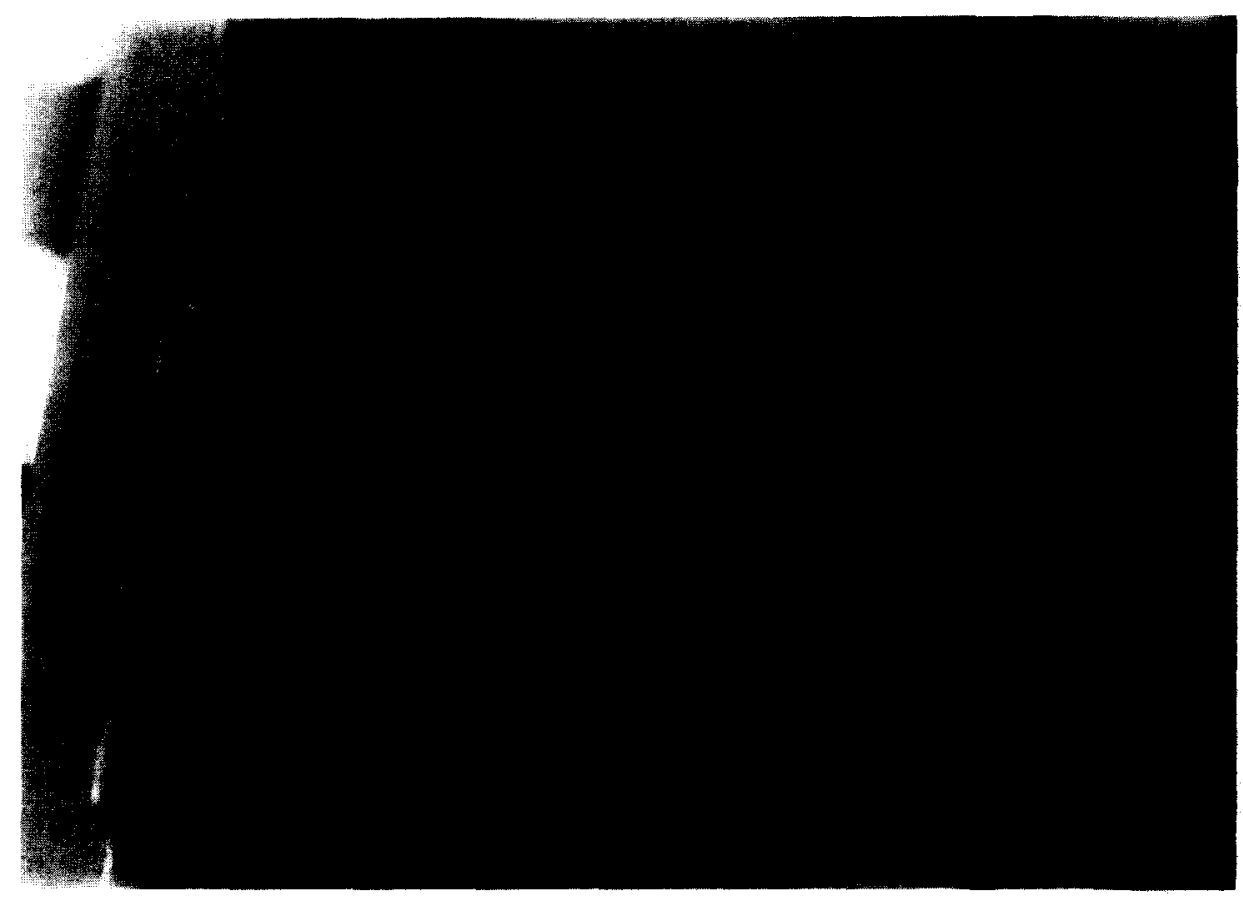

Fig. 5. Fatigue cracking at the root radii on both sides of the gear teeth in the solid spur gear.

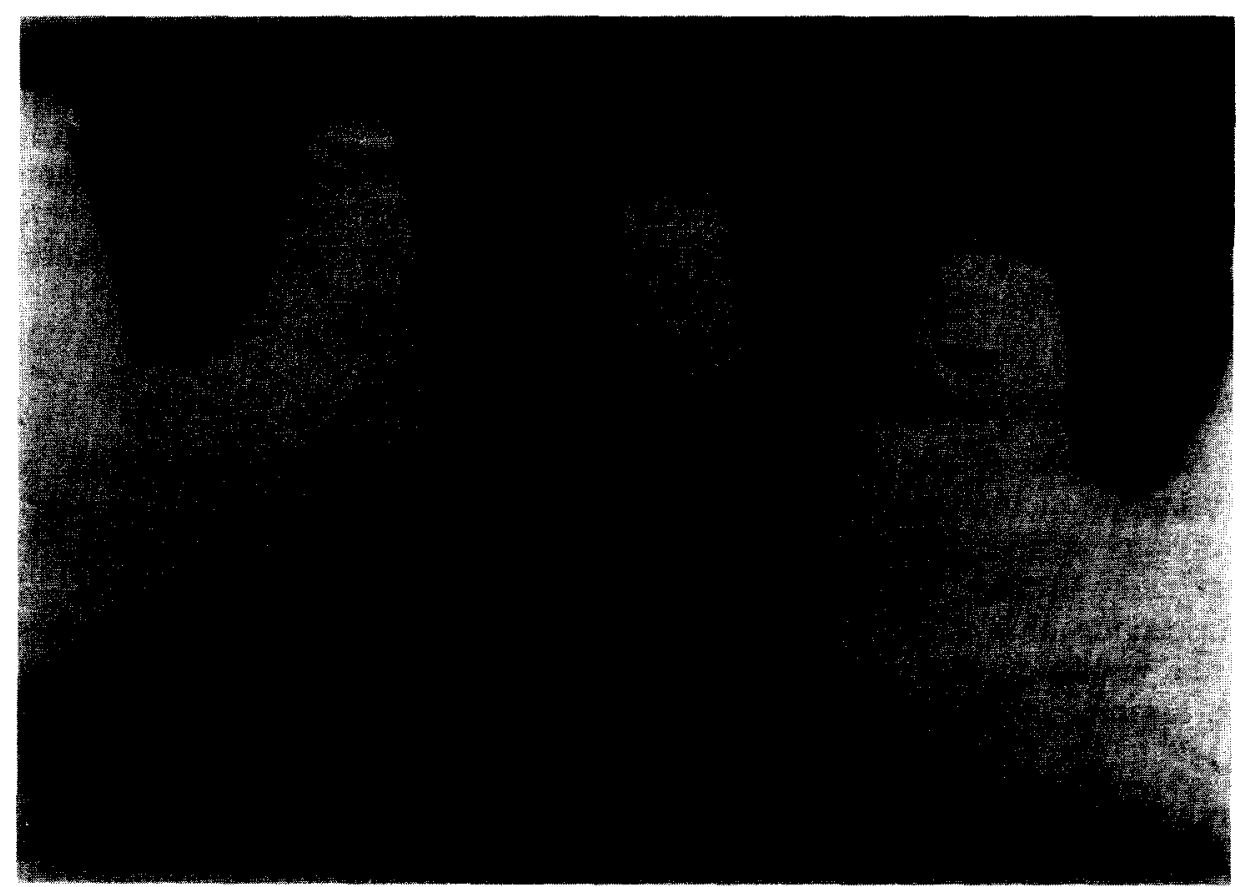

Fig. 6. Cracking at the tooth root radii adjacent to a threaded locating hole in the ring spur gear.

therefore lead to rapid failure. Any malfunction of the system should therefore be rectified and the gear-train realigned before resuming operation.

\section{SUMMARY}

Tooth bending fatigue is one of the most common modes of fatigue failure in gears. A number of actual case studies have been presented which indicate the occurrence of this 
failure mode in practice. From the preceding sections, therefore, the characteristics of tooth bending fatigue failure can be summarized as follows:

(a) Fatigue cracks originate at the root radii of the active side of the gear teeth.

(b) Cracks originate at the midpoint between the ends of the teeth under normal loading conditions, or where the highest stresses exist in the case of misalignment.

(c) The resulting crack path is normally L-shaped, progressing inwards to a point below the opposite root radius, and then outwards towards that radius.

(d) Due to the load shedding that occurs as the cracked tooth is deflected, tooth bending fatigue usually leads to failure of a number of adjacent gear teeth.

Acknowledgement-The assistance of the staff of the Metallurgical and Corrosion Services Programme, MATTEK, CSIR, in the preparation of this paper is gratefully acknowledged.

\section{REFERENCES}

1. J. E. Shigley, Mechanical Engineering Design (1st metric edn), Chaps 13 and 14, McGraw-Hill, Singapore (1986).

2. R. E. Peterson, Stress Concentration Factors, pp. 270-271, John Wiley, New York (1974).

3. L. E. Alban, Systematic Analysis of Gear Failures, pp. 86-94, American Society for Metals, Metals Park, OH (1985).

4. ASM Metals Handbook, Failure of Gears, Vol. 10, Failure Analysis and Prevention (8th edn), pp. 507-524 (1975).

5. P. J. L. Fernandes, Failure Analysis Report, Metallurgical and Corrosion Services, CSIR (1995).

6. M. S. Sherratt, Failure Analysis Report, Metallurgical and Corrosion Services, CSIR (1993).

7. A. James, Failure Analysis Report, Metallurgical and Corrosion Services, CSIR (1994). 